\title{
Synthesis and mesomorphic behaviour of lithocholic acid derivatives ${ }^{\dagger}$
}

\author{
V A E SHAIKH*, N N MALDAR and S V LONIKAR* \\ Shivaji University Centre for Postgraduate Studies, Kegaon, Solapur 413 002, India \\ "Present address: Maharashtra Institute of Technology, Paud Road, Kothrud, Pune 411 038, India
}

MS received 17 May 2001; revised 2 May 2003

\begin{abstract}
A series of liquid crystalline derivatives of lithocholic acid were prepared using simple chemical reactions involving the terminal functional group-hydroxyl at C-3 and/or carboxyl at C-24. Thus methyl -3(3-carboxy propionyl) lithocholate (I), 3-(3-carboxy propionyl) lithocholic acid (II), 3-acetyl lithocholic acid (III), 3-propionyl lithocholic acid (IV), 3-benzoyl lithocholic acid (V), 3-(4-nitrobenzoyl) lithocholic acid (VI), 3-cinnamoyl lithocholic acid (VII), methyl-3-(4-nitrobenzoyl) lithocholate (VIII) and 1,4-bis [cholan-24methoxy carbonyl-3-oxycarbonyl] butane (IX) were prepared in good yields and characterized by IR, NMR and polarizing optical microscopy. Compounds (I) and (IX) exhibited monotropic behaviour while the others were enantiotropic. Some of the compounds also showed a high tendency of super cooling. Compounds (V), (VI) and (IX) formed cholesteric phase while the remaining compounds displayed smectic phase.
\end{abstract}

Keywords. Mesomorphic; lithocholic acid; transition temperature.

\section{Introduction}

Tens of thousands of liquid crystalline materials are known (Kelkar and Hartz 1980). Several liquid crystalline compounds containing steroid unit have also been reported (Demus and Zaschke 1984). Studies on the liquid crystalline behaviour of homologous series of $p-n$-alkoxy benzoates (Dave and Vora 1970), trans $p-n$-alkoxy cinnamates (Dave and Vora 1971), $p-n$-alkoxy benzylidine- $p^{\prime}$-aminobenzoates (Dave and Kurian 1973a) and 6-n-alkoxy-2-naphthoates (Dave and Kurian 1973b) of cholesterol have appeared in the literature. Cholesterol itself is isotropic and only replacement of the hydroxyl with an appropriate substituent in the sterol can induce liquid crystalline behaviour. Lithocholic acid, [cholan-24-oic acid, 3-hydroxy- $(3 \alpha, 5 \beta)$ ], like all bile acids, possesses a steroid skeleton. It is a crystalline compound that melts to give clear isotropic liquid. In the present investigation several liquid crystalline aliphatic and aromatic ester derivatives of lithocholic acid were prepared. The derivatives prepared may be divided into four classes depending upon the nature and position of the substituent.

(I) Substituent at C-3 position that terminates the functionality. The lithocholic acid derivatives that belong to this category have a free carboxyl group at C-24 position. These derivatives can be used further for reaction with polymers containing free hydroxyl groups to confer liquid crystal-

\footnotetext{
*Author for correspondence

${ }^{\ddagger}$ Paper presented at the National Conference on Materials for the New Millenium-Matcon 2001, Cochin University of Science and Technology, Kochi, March 2001
}

line properties to the latter. The substituents used include acetyl, propionyl, benzoyl, $p$-nitrobenzoyl, and cinnamoyl.

(II) Substituent at C-3 position that creates a new functionality $(-\mathrm{COOH})$. This lithocholic acid derivative has twoterminal carboxyl groups, one at $\mathrm{C}-24$ position and the other at C-3 position (in fact, the substituent at C-3 is 3carboxy propionyl). It is mesomorphic and can be used further to prepare main chain liquid crystalline polymers (Shaikh et al 1999).

(III) Substituent at C-24 position that terminates the functionality and a substituent at $\mathrm{C}-3$ position that creates a new functionality $(-\mathrm{COOH})$. This is a monofunctional lithocholic acid derivative with $-\mathrm{COOH}$ group (3-carboxy propionyl) attached at $\mathrm{C}-3$ position while the $-\mathrm{COOH}$ group at $\mathrm{C}-24$ is blocked.

(IV) Substituents at C-3 and C-24 positions that terminate the functionality. Both the functional groups, $-\mathrm{OH}$ at $\mathrm{C}-3$ and $-\mathrm{COOH}$ at $\mathrm{C}-24$, are blocked in this case and, therefore, cannot be further used either to attach to polymer backbone or to prepare main-chain polymers, but would provide more insight into the mesomorphic behaviour of lithocholic acid based materials.

\section{Experimental}

Lithocholic acid (Aldrich Chemical Co, USA), acetyl chloride, propanoic acid, benzoyl chloride, succinic acid, (S.D. Fine Chemicals, India), adipoyl chloride (E. Merk), cinnamic acid and $p$-nitrobenzoic acid (Loba Chemie) were purchased from commercial sources and used as such unless mentioned otherwise. Propionyl chloride, cinnamoyl chloride, $p$-nitrobenzoyl chloride and succinic anhydride were pre- 
pared from the respective acids as per the conventional procedures (Furniss et al 1978). Other reagents and solvents obtained from commercial sources were purified according to standard procedures (Perrin et al 1980).

Melting point was determined by using electrically heated aluminium metal block melting point apparatus and are uncorrected. IR spectra were recorded on a Perkin Elmer 883 IR spectrophotometer, calibrated with polystyrene. Samples were taken in the form of $\mathrm{KBr}$ pellet, nujol mull or as solution in carbon tetrachloride as the case may be. Spectra were recorded in $4000-600 \mathrm{~cm}^{-1}$ range. ${ }^{13} \mathrm{C}-\mathrm{NMR}$ spectra were recorded on a Brucker $50 \mathrm{MHz}$ spectrometer at room temperature in deuteriated chloroform or DMSO. The chemical shifts were referenced to either $\mathrm{CDCl}_{3}$ or DMSO. ${ }^{1} \mathrm{H}-\mathrm{NMR}$ spectra were recorded using a Brucker $200 \mathrm{MHz}$ NMR spectrometer at $303 \mathrm{~K}$ in $\mathrm{CDCl}_{3}$ (concentration, $40 \mathrm{mg} / \mathrm{ml}$ ) using a $5 \mathrm{~mm}$-diameter NMR tube.

The thermal properties were determined by using LEITZ LABORLUX 11 POL microscope with polarized transmitted and incident light provision. Leitz micro heating stage 350 was coupled to the microscope. WILD MPS $0 \cdot 32 \times$ camera was attached to record photographically the birefringence pattern observed under microscope. Each sample was heated up to isotropization, then cooled to room temperature and again heated up to isotropization in a single checking. Heating and cooling rates for each sample were maintained at $10^{\circ} \mathrm{C} / \mathrm{min}$. The samples were further characterized by differential scanning calorimetry (DSC) with a Mettler TA 4000 series instrument. It consisted of a DSC cell coupled to Mettler TC 11 TA processor. Three runs, first heating (from room temperature to isotropization), cooling (to room temperature), and second heating (from room temperature to isotropization) were performed for all the samples. The heating and cooling rates were $10^{\circ} \mathrm{C} / \mathrm{min}$.

Methyl 3-(3-carboxypropionyl) lithocholate, (I), was prepared by the reaction of succinic anhydride with lithocholic acid methyl ester (LAMe). LAMe was prepared using a reported procedure with a slight modification (Ahlheim et al 1986). A mixture of lithocholic acid (5 g), anhydrous methanol $(25 \mathrm{ml})$, and concentrated hydrochloric acid $(0 \cdot 13 \mathrm{ml})$ was heated to reflux and stirred at reflux temperature for $2 \mathrm{~h}$. The stirring was continued overnight at room temperature. LAMe was isolated by filtration and purified by recrystallization from methanol (yield $93 \%$, m.p. $125^{\circ} \mathrm{C}$ ). A mixture of LAMe $(10 \mathrm{~g})$, succinic anhydride $(8 \mathrm{~g})$, and pyridine $(30 \mathrm{ml})$ was stirred in an inert atmosphere at $90^{\circ} \mathrm{C}$ for $24 \mathrm{~h}$. The product, (I), was isolated by filtration, washed with copious water and dried. It was further purified by Soxhlet extraction and recrystallized from acetone and dried under vacuum (yield $56 \%$, m.p. $163^{\circ} \mathrm{C}$ ). 3-(3-Carboxy propionyl) lithocholic acid, (II), was prepared in a similar manner as (I), except that lithocholic acid was used in place of LAMe (yield 59.3\%, m.p. $228^{\circ} \mathrm{C}$ ). 3-acetyl lithocholic acid, (III); 3-propionyl lithocholic acid, (IV); 3-benzoyl lithocholic acid, (V); 3-(4-nitrobenzoyl) lithocholic acid (VI); and 3-cinnamoyl lithocholic acid, (VII) were pre- pared using identical procedure in which lithocholic acid was treated with the respective acid chloride viz. acetyl chloride, propionyl chloride, benzoyl chloride, $p$-nitrobenzoyl chloride or cinnamoyl chloride in dichloroethane in presence of pyridine at $60-70^{\circ} \mathrm{C}$ under nitrogen atmosphere for $24 \mathrm{~h}$ ((III) (yield $90 \%$, m.p. $182^{\circ} \mathrm{C}$ ), (IV) (yield $62 \%$, m.p. $230^{\circ} \mathrm{C}$ ), (V) (yield $54 \%$, m.p. $260^{\circ} \mathrm{C}$ ), (VI) (yield $76 \%$, m.p. $218^{\circ} \mathrm{C}$ ), and (VII) (yield $55 \%$, m.p. $\left.238^{\circ} \mathrm{C}\right)$ ). Methyl 3-(4-nitrobenzoyl) lithocholate, (VIII), was prepared in similar manner as (VI) except that LAMe was used in place of lithocholic acid (yield $81 \%$, m.p. $205^{\circ} \mathrm{C}$ ). 1,4-Bis [cholan-24-methoxy carbonyl-3-oxycarbonyl] butane, (IX), was prepared by treating LAMe with adipoyl chloride (mole ratio $2: 1$ ) in presence of pyridine at room temperature for $24 \mathrm{~h}$ (yield $61 \%$, m.p. $158-159^{\circ} \mathrm{C}$ ).

\section{Results and discussion}

The general structure of the various lithocholic acid derivatives synthesized is shown in figure 1 . IR spectra of the lithocholic acid derivatives except (VIII) and (IX) showed the $-\mathrm{OH}$ stretching in the range $3300-3500 \mathrm{~cm}^{-1}$ due to the presence of $-\mathrm{COOH}$ group. The peaks due to acid carbonyl and ester carbonyl were observed in all spectra around $1700 \mathrm{~cm}^{-1}$ and $1730-1753 \mathrm{~cm}^{-1}$, respectively. In the compounds containing both acid as well as ester carbonyl (IVII) these peaks were seen as doublets. Aromatic esters (V, VI, VII and VIII) showed peaks in $700-900 \mathrm{~cm}^{-1}$ region which may be attributed to $\mathrm{C}-\mathrm{H}$ deformation of aromatic ring. In addition, (VI) and (VIII) showed absorbance at $\sim 1530 \mathrm{~cm}^{-1}$ which is a characteristic feature of $\mathrm{N}=\mathrm{O}$ stretching.

Proton NMR spectrum of LAMe (which was used to synthesize I, VIII, and IX) showed a strong singlet at $3.65 \mathrm{ppm}$ due to acetoxy methyl groups in addition to the usual peaks of lithocholic acid. LA derivative (I) showed multiplet at $2.65 \mathrm{ppm}$ due to two adjacent methylene groups of the succinoyl moiety in addition to the strong singlet at $3.65 \mathrm{ppm}$. Proton NMR spectrum of LA derivative (V) exhibited multiplets at $8 \cdot 1,7.5$ and $7 \cdot 1 \mathrm{ppm}$ which were assigned to the three non-equivalent protons of the benzene ring. LA derivative (VI) showed multiplet at 8.25 ppm, which was not well resolved and was assigned to the two non-equivalent protons of $p$-nitrobenzoyl group of (VI). Proton NMR spectrum of (IV) showed a multiplet at $2 \cdot 3 \mathrm{ppm}$ due to the methylene group adjacent to $-\mathrm{CH}_{3}$ and carbonyl. LA derivative (III) exhibited a sharp singlet at $2.05 \mathrm{ppm}$ that was assigned to the three equivalent acetyl protons. ${ }^{13} \mathrm{C}-\mathrm{NMR}$ spectrum of (III) revealed 26 lines for 26 carbons in the (III) molecule. The peaks due to $\mathrm{COOH}$ and $\mathrm{OCOCH}_{3}$ were seen at 171.01 and $74.7 \mathrm{ppm}$, respectively. The remaining ${ }^{13} \mathrm{C}$ signals were similar to those observed in lithocholic acid. LA derivative (VIII) exhibited a sharp singlet at $3.65 \mathrm{ppm}$ and a multiplet at $8.25 \mathrm{ppm}$ assigned to methyl 
protons of the ester group and the $p$-nitrobenzene moiety, respectively. LA derivative (IX) showed multiplets at $2.3 \mathrm{ppm}$ and $1.65 \mathrm{ppm}$ which could be assigned to the non-equivalent methylene protons of the adipoyl moiety in addition to a strong singlet at $3.65 \mathrm{ppm}$ attributed to the three equivalent methyl ester protons. The results of ${ }^{1} \mathrm{H}-\mathrm{NMR}$ and ${ }^{13} \mathrm{C}-\mathrm{NMR}$ studies of these compounds are summarized in table 1 .

Mesomorphic behaviour of the lithocholic acid derivatives was studied by polarizing optical microscopy and<smiles>[R][R4](=O)OC1CCC2(C)C(CCC3C4CCC(C(C)CCCC([R])=O)C4CCC32)C1</smiles>

(I) - (VIII)
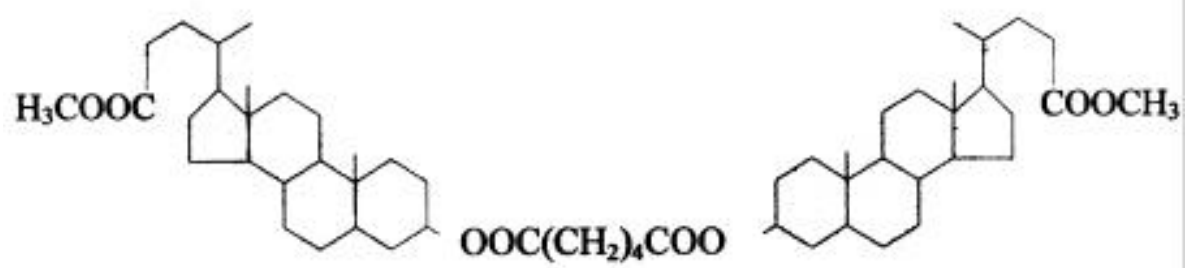

(IX)

Figure 1. General structure of lithocholic acid derivatives. (I) $\mathrm{R}^{1}=-\mathrm{CH}_{3}, \mathrm{R}^{2}=$ HOOCCH $\mathrm{CH}_{2}^{-}$; (II) $\mathrm{R}^{1}=\mathrm{H}, \mathrm{R}^{2}=\mathrm{HOOCCH}_{2} \mathrm{CH}_{2}-$; (III) $\mathrm{R}^{1}=\mathrm{H}, \mathrm{R}^{2}=-\mathrm{CH}_{3}$; (IV) $\mathrm{R}^{1}=\mathrm{H}$, $\mathrm{R}^{2}=-\mathrm{CH}_{2} \mathrm{CH}_{3}$; (V) $\mathrm{R}^{1}=\mathrm{H}, \mathrm{R}^{2}=0$ O $;(\mathrm{VI}) \mathrm{R}^{1}=\mathrm{H}, \mathrm{R}^{2}=-\mathrm{NO}_{2} ; \quad(\mathrm{VII}) \mathrm{R}^{1}=\mathrm{H}, \mathrm{R}^{2}=$ $-\mathrm{CH}=\mathrm{CH}-\mathrm{O} ;(\mathrm{VIII}) \mathrm{R}^{1}=-\mathrm{CH}_{3}, \mathrm{R}^{2}=-\mathrm{O}-\mathrm{NO}_{2}$.

Table 1. Summary of NMR studies of lithocholic acid derivatives.

\begin{tabular}{|c|c|c|}
\hline $\begin{array}{l}\text { Lithocholic acid } \\
\text { derivative }\end{array}$ & Substituent & $\begin{array}{l}\text { Peak position }(\mathrm{ppm}) \text { and } \\
\text { nature of peak }\end{array}$ \\
\hline LAMe & $----\mathrm{COOCH}_{3}$ & $\mathrm{~S}, \delta=3 \cdot 65$ \\
\hline I & $----\mathrm{COOCH}_{3}$ & $\mathrm{~S}, \delta=3 \cdot 65$ \\
\hline & $\mathrm{HOOC} \mathrm{CH}_{2} \mathrm{CH}_{2} \mathrm{COO}-$ & $M, \delta=2 \cdot 65$ \\
\hline II & $\begin{array}{l}\mathrm{HOOC} \mathrm{CH}_{2} \mathrm{CH}_{2} \mathrm{COO}- \\
---\mathrm{CH}_{2} \mathrm{COOH}\end{array}$ & $\mathrm{M}, \delta=2 \cdot 5$ \\
\hline III & $\mathrm{CH}_{3} \mathrm{COO}-$ & $\mathrm{S}, \delta=2.05(171.01,74 \cdot 7)^{*}$ \\
\hline IV & $\mathrm{CH}_{3} \mathrm{CH}_{2} \mathrm{COO}-$ & $\mathrm{M}, \delta=2 \cdot 3,1 \cdot 2$ \\
\hline $\mathrm{V}$ & $0-\mathrm{COO}$ & $\mathrm{M}, \delta=8 \cdot 1,7 \cdot 5,7 \cdot 1$ \\
\hline VI & $\mathrm{O}_{2} \mathrm{~N}-O-\mathrm{COO}_{-}$ & $\mathrm{M}, \delta=8 \cdot 25$ \\
\hline \multirow[t]{2}{*}{ VIII } & $-------\mathrm{COOCH}_{3}$ & $S, \delta=3.65$ \\
\hline & $\mathrm{O}_{2} \mathrm{~N}-O-\mathrm{COO}_{-}$ & $\mathrm{M}, \delta=8 \cdot 25$ \\
\hline IX & $-\mathrm{OOC}\left(\mathrm{CH}_{2}\right)_{4} \mathrm{COO}-$ & $\mathrm{M}, \delta=2 \cdot 3,1 \cdot 65$ \\
\hline
\end{tabular}

----linked to C-24 of LA, -linked to C-3 of LA, $*{ }^{13} \mathrm{C}-\mathrm{NMR}$ data. 
differential scanning calorimetry. Transition temperatures of the compounds, determined by using polarizing microscope equipped with a controlled microheating stage, are given in table 2 .

The mesophases observed were compared with standard plates before assigning the texture (Demus and Richter 1978). LAMe is not mesomorphic, it melts at $125^{\circ} \mathrm{C}$ but does not exhibit mesophase. All the other LA derivatives (I to IX) are mesomorphic. Most of them also show a high tendency of super cooling. LA derivative (I) displayed monotropic smectic behaviour. Mesophase was observed at $109^{\circ} \mathrm{C}$ while cooling the isotropic melt. DSC thermogram, in heating mode, showed a single endotherm at $157^{\circ} \mathrm{C}$ representing isotropization. During cooling run also it showed one exotherm at $109-110^{\circ} \mathrm{C}$ which was attributed to mesophase formation as judged by observation under polarizing microscope. The absence of two distinct exotherms is, probably, because the mesophase is retained up to room temperature. LA derivative (II) also showed mesomorphic properties similar to (I). It melted directly during first heating around $236^{\circ} \mathrm{C}$ with slight brightness just before melting. The sample was heated $5^{\circ}$ above its melting point, held at this temperature for $5 \mathrm{~min}$, and then cooled at a rate of $10^{\circ} \mathrm{C} / \mathrm{min}$. Highly coloured birefringence was observed from 170 $167^{\circ} \mathrm{C}$ while cooling. A comparison of this texture with

Table 2. Transition temperatures of lithocholic acid derivatives.

\begin{tabular}{llll}
\hline $\begin{array}{l}\text { Lithocholic } \\
\text { acid } \\
\text { derivatives }\end{array}$ & \multicolumn{2}{c}{ Transition temp. ${ }^{\circ} \mathrm{C}$} & \\
\cline { 2 - 3 } & \multicolumn{1}{c}{ C-LC } & LC-I & Phase \\
\hline I & $(109)$ & 157 & $\mathrm{~S}$ \\
II & $120,(167),(135)^{*}$ & 236 & $\mathrm{~S}$ \\
III & $95,125^{*},(130),(120)^{*}$ & 176 & $\mathrm{~S}$ \\
IV & 195 & 220 & $\mathrm{~S}$ \\
V & $235,(220)$ & 260 & $\mathrm{Ch}$ \\
VI & 180 & 218 & $\mathrm{Ch}$ \\
VII & 220 & 237 & not clear \\
VIII & 115 & 213 & $\mathrm{~S}$ \\
IX & $(133)$ & 163 & Ch \\
\hline
\end{tabular}

C-LC crystal-to-liquid crystal transition, LC-I liquid crystal-toisotropic transition, *texture change, () cooling. standard specimen suggested that it most probably was smectic $\mathrm{G},\left(\mathrm{S}_{\mathrm{G}}\right)$, mosaic texture. This texture remained up to $135^{\circ} \mathrm{C}$ then changed into a new, different, unidentifiable texture which was retained up to room temperature. On second heating, smectic $\mathrm{A},\left(\mathrm{S}_{\mathrm{A}}\right)$, batonnets were observed from $120^{\circ} \mathrm{C}$ onwards. The birefringence disappeared to give isotropic melt at $236^{\circ} \mathrm{C}$.

LA derivative (III) showed smectic phase with broken fan texture at $130^{\circ} \mathrm{C}$ on heating as well as on cooling the isotropic melt (figure 2). During cooling, the texture changed at lower temperature into an unidentifiable texture. LA derivative IV, a higher homologue of (III), showed smectic phase of similar broken fan shaped texture but, as expected, at higher temperature, $195^{\circ} \mathrm{C}$. However, mesophase was not observed during cooling, probably because of the super cooling. These observations are corroborated by DSC results shown in figure 3. The heating curve shows two endotherms corresponding to crystal-mesophase and mesophase-isotropic transitions, while the cooling curve is featureless.

The aromatic derivatives of LA, (V) and (VI) showed cholesteric phase at $235^{\circ} \mathrm{C}$ and $180^{\circ} \mathrm{C}$, respectively. On cooling mesophase appeared in case of (V) at $220^{\circ} \mathrm{C}$ indicating some tendency for super cooling. On reheating, the birefringence increased from $180^{\circ} \mathrm{C}$ onwards. Heating and cooling cycles were repeated with similar observations. The super cooling was more prominent in case of (VI) which did not reveal mesophase formation on cooling the isotropic melt. This inference was further substantiated from the DSC results. The heating curve showed two endotherms corresponding to crystal-mesophase and mesophase-isotropic transitions, while the cooling curve was featureless. LA derivative (VII) showed a mesophase without clearly identifiable texture at $215^{\circ} \mathrm{C}$ on first heating and from $220^{\circ} \mathrm{C}$ on cooling. The mesophase-isotropic transitions were found to be $260^{\circ} \mathrm{C}, 237^{\circ} \mathrm{C}$ and $218^{\circ} \mathrm{C}$ for (V), (VII), and (VI), respectively. This is not expected as the average mesophase-isotropic transition temperature of $p$ - $n$-alkoxycinnamates of cholesterol $\left(251 \cdot 8^{\circ} \mathrm{C}\right)$ has been reported to be higher than that of $p$-n-alkoxybenzoates of cholesterol $\left(224^{\circ} \mathrm{C}\right.$ ) (Dave and Kurian 1973b). However, the observed mesophase-isotropic transition temperatures for (V) $260^{\circ} \mathrm{C}$, (VII) $237^{\circ} \mathrm{C}$, and (VI)
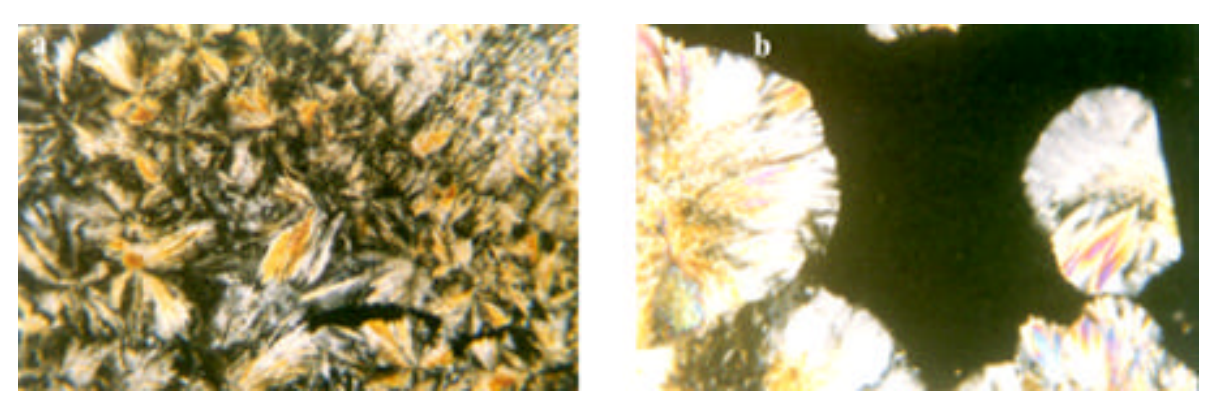

Figure 2. Photomicrographs (crossed polars) of III (a. heating, $120^{\circ} \mathrm{C}$; b. cooling, $\left.130^{\circ} \mathrm{C}\right)$. 


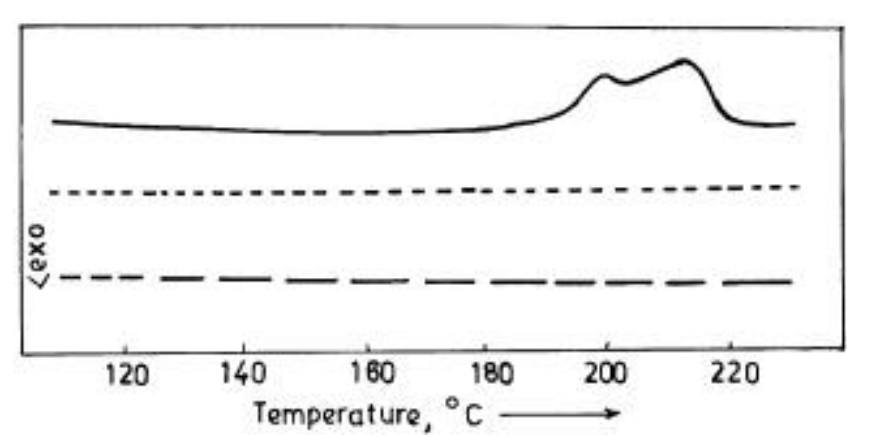

Figure 3. DSC thermogram of IV (— first heating; ---- cooling; --- second heating).

$218^{\circ} \mathrm{C}$ in the present investigation correlate with the electron-withdrawing ability of the substituents (benzoyl $<$ cinnamoyl $<p$-nitrobenzoyl). Also it should be noted that the cholesterol derivatives ( $p$ - $n$-alkoxy cinnamates or $p$ - $n$-alkoxybenzoates) have no free polar functional group while the LA derivatives V, VI and VII have a free carboxyl group at $\mathrm{C}-24$ position.

LA derivative (VIII) showed mesophase formation from $100^{\circ} \mathrm{C}$ and mesophase-isotropic transition occurred at $213^{\circ} \mathrm{C}$ which are lower than the corresponding temperatures $\left(180^{\circ} \mathrm{C}\right.$ and $\left.218^{\circ} \mathrm{C}\right)$ for (VI). This probably is because the latter has a terminal $-\mathrm{COOH}$ group while the former has $-\mathrm{COOCH}_{3}$. LA derivative (IX) showed monotropic behaviour, mesophase appearing at $135^{\circ} \mathrm{C}$ on cooling the isotropic melt.

\section{Conclusion}

Non mesomorphic lithocholic acid can be converted into liquid crystalline compounds by appropriate derivatiza- tion. This was achieved by introducing terminal substituents in lithocholic acid.

\section{Acknowledgement}

The authors thank the Department of Science and Technology, New Delhi, for financial assistance through grant no. SP/S1/G-72/90.

\section{References}

Ahlheim M, Hallensleben M L and Wurm H 1986 Polym. Bull. 15497

Dave J S and Vora R A 1970 in Liquid crystals and ordered fluids (eds) J F Johnson and R S Porter (New York: Plenum) p. 477

Dave J S and Vora R A 1971 Mol. Cryst. Liq. 14319

Dave J S and Kurian G 1973a Mol. Cryst. Liq. 24347

Dave J S and Kurian G 1973b Liquid crystal (ed.) S Chandrasekhar (Bangalore: Indian Academy of Sciences) p. 427

Demus D and Richter L 1978 Texture of liquid crystal (New York: Verlag Chemie)

Demus D and Zaschke H 1984 Flussige kristalle in tabellen (Leipzig: VEB Deutscher Verley Fur Grundstoffindustrie)

Furniss B S, Hannaford A J, Rogersm V, Smith P W G and Tatchell A R (eds) 1978 Vogel's textbook of practical organic chemistry (England: Longman publ.) 4 ed., p. 497

Kelkar H and Hartz R 1980 Handbook of liquid crystals (Weinheim: Verley Chemie)

Perrin D D, Armarego W L F and Perrin D R V 1980 Purification of laboratory chemicals (New York: Pergamon Press) 2nd ed.

Shaikh V A E, Ubale V P, Maldar N N and Lonikar S V 1999 Polymer beyond AD 2000 (ed) A K Ghosh (New Delhi: The Society for Polymer Science) p. 174 